\title{
Correction to: Recent advances in multiple criteria decision making techniques
}

\author{
Yulin $\mathrm{He}^{1} \cdot$ Xizhao Wang $^{1} \cdot$ Joshua Zhexue Huang $^{1}$
}

Published online: 1 December 2021

○) Springer-Verlag GmbH Germany, part of Springer Nature 2021

\section{Correction to: Int. J. Mach. Learn. \& Cyber. https://doi.org/10.1007/s13042-015-0490-y}

This editorial was not for a special issue but for a regular issue with a special focus, selected from regularly accepted papers. Due to some reason, the selected papers were not put together to form an issue.

All mentioned articles in the editorial had ever been published in different regular issues. Their specific details are listed below.

The article "Generalized intuitionistic fuzzy multiplicative interactive geometric operators and their application to multiple criteria decision making" was published in Volume 7, Issue 6, December 2016.

The article "Interval valued hesitant fuzzy uncertain linguistic aggregation operators in multiple attribute decision making" was published in Volume 7, Issue 6, December 2016.

The article "Dual hesitant fuzzy group decision making method and its application to supplier selection" was published in Volume 7, Issue 5, October 2016.

The original article can be found online at https://doi.org/10.1007/ s13042-015-0490-y.

Yulin $\mathrm{He}$

csylhe@126.com

Xizhao Wang

xzwang@szu.edu.cn

Joshua Zhexue Huang

zx.huang@szu.edu.cn

1 Big Data Institute, College of Computer Science and Software Engineering, Shenzhen University, Shenzhen 518060, China
The article "On inclusion measures of intuitionistic and interval-valued intuitionistic fuzzy values and their applications to group decision making" was published in Volume 7, Issue 5, October 2016.

The article "Hesitant fuzzy linguistic linear programming technique for multidimensional analysis of preference for multi-attribute group decision making" was published in Volume 7, Issue 5, October 2016.

The article "The aggregation operators based on the 2-dimension uncertain linguistic information and their application to decision making" was published in Volume 7, Issue 6, December 2016.

The article "Simplified neutrosophic harmonic averaging projection-based method for multiple attribute decisionmaking problems" was published in Volume 8, Issue 3, June 2017.

The article "Grey stochastic multi-criteria decision-making based on regret theory and TOPSIS" was published in Volume 8, Issue 2, April 2017.

The article "Multiple attribute group decision making based on generalized power aggregation operators under intervalvalued dual hesitant fuzzy linguistic environment" was published in Volume 7, Issue 6, December 2016. 